\title{
Analisis Unit Cost pada Menu Makanan yang Disajikan dalam Penyelenggaraan Makanan di SD/SMP Islam Terpadu Al-Fahmi Kota Palu
}

\section{Analysis Of Cost Units On The Food Service Menu Presented In The Food Service At Smpit Al-Fahmi, Palu City}

\author{
Nurjaya $^{1}$, Irawati $^{2}$, Ketrin $^{1}$ \\ ${ }^{1}$ Poltekkes Kemenkes Palu \\ ${ }^{2}$ RSUD Madani Palu \\ (jayajastal@yahoo.com, 081340846207)
}

\begin{abstract}
ABSTRAK
Perhitungan unit cost berperan penting dalam efektifitas dan efisensi anggaran suatu organisasi. Tujuan penelitiaan ini menganalisis unit cost pada menu makanan yang disajikan dalam penyelenggaraan makanan di SD/SMP Islam Terpadu Al- Fahmi Kota Palu. Jenis penelitian yang digunakan dalam penelitian ini adalah penelitian kuantitatif dengan pendekatkan deskriptif dengan tahnik wawancara dan pengumpulan sampel pada penelitian ini adalah seluruh menu makanan yang disajikan di SD/SMP IT Al-Fahmi Kota Palu. Hasil penelitian menunjukan bahwa pada penyelenggaraan makanan di SD/SMP IT Al-fahmi Kota Palu adalah melayani 1027 orang konsumen, dengan 5 hari siklus menu, terdapat standar menu/resep, dan harga satuan makanan yang berlaku adalah harga pasar. Tenaga yang ada berjumlah 24 orang, aspek biaya tenaga terdiri atas gaji, biaya insentif, transportasi, dan tunjangan kesehatan. Biaya overheadterdiri dari biaya tetap dengan barang dengan pemakaian 3 tahun, 10 tahun dan 15 tahun. Biaya tidak tetap yaitu barang habis pakai, listrik dan bahan bakar serta penyusutan. Sehingga didapatkan biaya makanan per orang per hari adalah Rp.9.661,83,-, biaya tenaga per orang perhari adalahRp.1.982,91, biaya overhead per orang per hari adalah 265.73,-, unit cost pada Rp.14.012.31/orang/hari, dan profit yaitu Rp.2.101,84,-/orang/hari. Diharapkan unit cost yang telah dihitung dapat menjadi pertimbangan dalam perencanaan anggaran sehingga efektifitas dan efisiensi dapat ditingkatkan.
\end{abstract}

Kata kunci : Unit cost, penyelenggaran makanan

\section{ABSTRACT}

Unit cost calculation plays an important role in the effectiveness and efficiency of an organization's budget. The purpose of this research is to analyze the unit cost in the food menu served in the organization of food in the Al-Fahmi Integrated Islamic Elementary / Middle School in Palu City. This type of research used in this research is a quantitative study with descriptive approach with interview techniques and sample collection in this study is the entire menu of food served at SD / SMP IT AlFahmi, Palu City. The results showed that the implementation of food in SD / SMP IT Al-Fahmi Palu City is serving 1027 consumers, with 5 days menu cycle, there is a standard menu / recipe, and the prevailing food unit price is the market price. The available workforce is 24 people, aspects of labor costs consisting of salaries, incentive costs, transportation, and health benefits. Overhead costs consist of fixed costs with goods that use 3 years, 10 years and 15 years. Variable costs are consumables, electricity and fuel and depreciation. So that the obtained cost of food per person per day is Rp.9,661.83, -, labor costs per person per day is Rp.1,982.91, overhead costs per person per day is 
265.73, -, unit cost at Rp.14,012.31 / person / days, and profit is Rp. 2,101.84, - / person / day. It is expected that the calculated unit cost can be considered in budget planning so that effectiveness and efficiency can be increased.

\section{Keywords : Unit cost, food service}

\section{PENDAHULUAN}

Pelayanan gizi intitusi merupaan penyelenggaraan makanan yang disajikan di suatu intitusi (hotel, restoran, kafe, asrama, perkantoran dan lain-lain), yang maknannya disajikan dalam jumlah yang besar, dimana jumlah porsi makanan yang diolahtelah ditentukan terlebih dahulu.Sistem Penyelenggaraan Makanan Institusi/massal (SPMI/M) adalah penyelenggaraan makanan yang dilakukan dalam jumlah besar atau massal.Jumlah makanan yang diselenggarakan disetiap negara memiliki batasan yang berbeda-beda, sesuai dengan kesepekatan masing-masing.Di Inggris disebut penyelenggaraan makanan banyak apabila jumlah produksi 1000 porsi perhari, dan di Jepang 3000-5000 porsi sehari.Sedangkan di Indonesia penyelenggaraan makanan banyak atau massal yang digunakan adalah bila penyelenggaraan lebih dari 50 porsi sekali pengolahan. Sehingga jika 3 kali makan dalam sehari, maka total porsi yang diselenggarakan adalah 150 porsi sehari. ${ }^{1}$

Jenis pelayanan gizi institusi sendiri terbagi atas beberapa macam, yaitu: penyelenggaraan makanan pada pelayanan kesehatan, anak sekolah (school feeding), asrama, institusi sosial, makanan khusus, industri transportasi, industri tenaga kerja, institusi komersial dan penyelenggaraan makanan darurat. $^{2}$ Dalam kegiatan penyelenggaraan makanan dalam jumlah yang besar pada instiitusi-institusi, terutama diperkotaan disebabkan oleh kurangnya ketersediaan waktu untuk menyediakan makanan bagi keluarga karana semakin banyaknya parawanita yang bekerja di luar rumah untuk memenuhi kebutuhan kelurga. Selain itu faktor jarak juga mempengaruhi. Dituntut suatu keseriusan dan perhatian dari para pengolah makanan dalam manejemen penyelenggaraan makanan masal atau institusi, karena banyak unsur yang harus dikelola dengan baik, yaitu menyangkut keseluruhan unsur manajemen, antara lain unsur tenaga kerja (man), biaya (money), bahan maknan (material), peralatan (machine), sistem produksi (mathod), dan sistem pemasaran (marketing). ${ }^{2}$ Semua itu berlaku disemua istitusi penyelenggaraan makanan, salah satu contohnya adalah penyelenggaraan makanan disekolah.

Dewasa ini penyediaan makanan anak sekolah telah menjadi kebutuhan penting bagi semua warga sekolah, karena akibat waktu sekolah yang cukup panjang sehingga anak belum sempat sarapan atau makan di rumah. Di negara-negara maju makanan anak sekolah dikenal dengan istilah school feeding yangsangat diperhatikan penyelenggaraan. Program sarapan ataupun makan siang disekolah biasanya dipersiapkan dan diolah didapur sekolah atau di luar gedung sekolah. ${ }^{2}$ 
Sesuai dengan peraturan yang berlaku, menurut pusat pendidikan sumber daya manusia kesehatan edisi tahun 2018, awalnya program makanan anak sekolah dimaksudkan untuk membantu meningkatkan status gizi anak-anak sekolah yang keluarganya kurang mampu. Namun kebutuhan makanan di sekolah lambat laun menjadi kebutuhan semua warga sekolah, sebagai akibat waktu sekolah yang cukup panjang ataupun anak tidak sempat sarapan di rumah sebelum ke sekolah. ${ }^{3}$

Bentuk pelayanan makanan di sekolah memiliki karakteristik memberikan pelayanan untuk makanan pagi/siang/sore ataupun makanan kecil/ makanan pelengkap, dimana makanan dapat disediakan melalui kantin sekolah dengan syarat : makanan yang disajikan bergizi, dan sebagai bahan pendidikan atau penyuluhan bagi anak serta mendorong membiasakan anak untuk memilih makanan yang bergizi untuk konsumsinya, makanan yang dipersiapkan tidak berorientasi pada keuntungan atau swakelola, tetapi diarahkan untuk pendidikan/penyuluhan dan perubahan perilaku anak terhadap makanan. Oleh karena itu dalam mengelola makanan kantin ini, diikut sertakan peran orang tua agar dapat diikuti kebiasaan makan anak di rumah.Lokasi dan ruang kantin disediakan sedemikian rupa sehingga anak dapat mengembangkan kreasinya dan dapat mendiskusikan pelajarannya. Dan pada pelayanan makanan di sekolah dipersiapkan dalam keadaan bersih dan higienis dan Menciptakan manajemen yang baik sehingga dapat dicapai keseimbangan pembiayaan kantin yang memadai. ${ }^{1} \quad$ Dimana pada penyajian makanan di sekolah juga perlu memperhatihakan segi penyajian, karena pada dasarnya anak susah untuk diajak makan. Sehingga makanan yang diberi disajikan dan dibentuk secara menarik untuk menarik perhatian anak untuk makan.

Penyelenggaraan maknan pada anak sekolah dapat memberikan manfaat antara lain dapat menyediakan makanan bagi anak sekolah, memperbaiki status gizi anak dan atau menapai kesehatan yang optimal, meningkatkat semangat belajar anak, membiasakan anak sarapan dan makan tepat waktu, dan membantu anak sekolah agar tidak jajan sembarangan. Untuk memenuhi manfaat tersebut, penerapan prinsip penyelenggaraan mapkanan harus diperhatikan yaitu, dengan menghasilkan makanan yang berkualitas baik, menyediakan menu seimbang dan bervariasi sesuai dengan harapan konsumen, memberikan pelayanan yang cepat dan menyenangkan, memberikan layanan dengan harga yang layak, memberikan layanan dengan fasilitas yang memadai serta mengelola pengadaan makanan dengan menggunakan standar higene dan sanitasi. ${ }^{4}$

Dari hasil penelitian yang dilakukan tentang analisi menu makanan biasa di RSUD Massenrempullu Kabupaten Enrekang, diperoleh hasil bahwa analisis food cost perhari adalah sebesar Rp 38.061,54/orang dan $30 \%$ tambahan untuk bumbu. Biaya seperti ini rumah sakit sudah dapat menyediakan menu 
yang dapat memenuhi kecukupan gizi dengan energi 2249 kilokalori $^{5}$. Sedangkan penelitian tentang gambaran sistem penyelenggaraan makanan di pondok pesantren putri Ummul Mukinin Makasar, didapatkan biaya makan santri hanya sebesar Rp. 4.981,92,-/ orang dalam satu hari, tentu saja biaya tersebut sangat kurang. Dari hasil perhitugan unit cost diteukan total biaya makanan perhari ialah Rp.6.883,30,-/santri. ${ }^{6}$

Di kota Palu terdapat sekolah yang telah melaksanankan penyelenggaraan makan siang di sekolah, salah satunya adalah SD/SMPIslam Terpadu Al-Fahmiberdiri pada tahun 2013 bertempat di Jl.Gelatik No.88, Kelurahan Birobuli Utara, Kecamatan Palu Selatan, Kota Palu, Provinsi Sulawesi Tengah. Pada tahun ajaran 2018/2019 siswa SD/SMPIslam Terpadu Al-Fahmi berjumlah 979 siswa yang terdiri dari 830 siswa SD dan 149 siswa SMP. Dalam penyelenggaraan makanan SD/SMPIslam Terpadu Al-Fahmi katering di bina langsung oleh Pembina Yayasan Al-Fahmi yang dibantu oleh dua orang pengarah. Kemudian dari pembina yayasan langsung dikelola oleh 3 pengelola yaitu pengelola I yang bertanggung jawab sebagai maneger SDM,Perlengkapan, dan Kebersihan, pengelola II yang bertanggung jawab sebagai manager teknis, dan pengelola III yang bertanggung jawab sebagai konsultan gizi di katering SD/SMPIT Al-Fahmi. Pengelola I dan II mengontrol dan mengatur bagian admisistrasi, logistik, olahan, distribusi, peralatan, dan sanitasi . Untuk bagian olahan makanan di awasi langsung oleh satu orang yang bertanggung jawab dalam pengolahan lauk utama, lauk pendamping, nasi, sayur dan buah serta snack dimana pada proses pengolahan makanan tersebut dibantu oleh 16 orang penjamah makanan.

Dalam manajemen sistem penyelenggaraan makanan di SD/SMP Islam Terpadu Al-Fahmi perencanaan menu dilakukan oleh Ahli Gizi.Siklus menu yang digunakan adalah siklus menu 5 hari. Siklus menu tersebut digunakan untuk periode tertentu, tetapi sewaktu-waktu dapat dirubah berdasarkan permintaan klien (siswa). Menu yang di tetapkan di katering SD/SMPIslam Terpadu Al-Fahmi adalah menu biasa dengan frekuensi hidangan makanannya 1x selinga dan $1 \mathrm{x}$ makan utama. Namun satu hal yang belum tergambar dalam penyelenggaraan makan di SD/SMP Islam Terpadu Al-Fahmi Kota Palu adalah unit cost menu yang disajikan.

Berdasarkan uraian di atas, maka peneliti tertarik untuk meneliti analisis Unit Cost Pada Menu Makanan Yang Disajikan Dalan Penyelenggaraan Makanan Di SD/SMP Islam Terpadu Al-Fahmi Kota Palu 2019.

\section{METODE PENELITIAN}

Jenis penelitian yang dilakukan adalah penelitian kuantitatif dengan pendekatan deskriptif bertempat di SD/SMP Islam Terpadu Al-Fahmi pada bulan Juni Tahun 2019. Populasi dan sampel dalam penelitian ini adalah semua hidangan pada menu yang disajikan di SD/SMP Islam Terpadu Al Fahmi selama 1 siklus penyajian (5 hari). 
Analisis data yang digunakan menggunakan analisis univariat. Data dalam penelitian ini disajikan dalam bentuk tabel matriks

\section{HASIL}

\section{a. Biaya Makanan}

Hasil data yang didapatkan di SD/SMP Al-Fahmi yang berkaitan dengan biaya makanan adalah terdapat peraturan makan yaitu siklus 5 hari dapat dilihat pada lampiran 3. Jumlah konsumen 1027 orang dimana terdapat standar menu/resep,harga satuan makanan. Yang berlaku adalah harga pasar, yang berarti dalam hal ini pengadaan bahan makanan tidak dengan cara melalui rekanan atau pihak ketiga tetapi dengaan cara pembelian langsung ke pasar. Khusus untuk selingan berupa kue pengadaannya dengan cara rekanan atau telah terjalin kontrak, dimana harga dari semua snack yang ada yaitu dengan harga Rp.1.500/biji. Dalam sekali pemesanan diketahui jumlah pesanan adalah 1500 biji. Yang mana pemesanan dilakukan melebihi jumlah konsumen. Sisa dari snack yang berlebih dapat dikonsumsi oleh guru, pekerja, dan siswa yang berada di sekolah sampai sore hari. Berikut adalah perhitungan biaya makanan untuk 1027 konsumen pada penyelenggaraan makanan di SD/SMP IT Al- Fahmi Kota Palu tahun 2019.

\begin{tabular}{|c|c|c|c|c|c|}
\hline Bahan Makanan & $\begin{array}{c}\text { Berat } \\
\text { bersih }(\mathrm{gr})\end{array}$ & $\begin{array}{c}\text { Berat } \\
\text { kotor }(\mathrm{gr})\end{array}$ & $\begin{array}{c}\text { Kebutuhan bahan } \\
\text { makanan }\end{array}$ & $\begin{array}{l}\text { Harga satuan } \\
\text { (Rp) }\end{array}$ & $\begin{array}{c}\text { Jumlah biaya } \\
(\mathrm{Rp})\end{array}$ \\
\hline \multicolumn{6}{|c|}{ Perhitungan Biaya Bahan Makanan Menu I } \\
\hline Roti Coklat & 100 & 100 & $1.500 \mathrm{bj}$ & $1.500 / \mathrm{bj}$ & $2.250 .000,0$ \\
\hline Susu kental manis & 44 & 44 & $45188 \mathrm{gr}$ & $9.000 / 370 \mathrm{gr}$ & $1.099 .167,6$ \\
\hline Beras & 60 & 60 & $61,62 \mathrm{~kg}$ & $10.000 / \mathrm{kg}$ & $616.200,0$ \\
\hline Ayam & 50 & 86 & $88,32 \mathrm{~kg}$ & $30.000 / \mathrm{kg}$ & 2.649 .600 \\
\hline Telur ayam & 10 & 10 & $10,27 \mathrm{~kg}$ & $36.000 / \mathrm{kg}$ & $369.720,0$ \\
\hline Tepung terigu & 14 & 14 & $14,38 \mathrm{~kg}$ & $8.000 / \mathrm{kg}$ & $115.040,0$ \\
\hline Tepung maizena & 4 & 4 & $4,11 \mathrm{~kg}$ & $18.500 / \mathrm{kg}$ & $76.035,0$ \\
\hline Tahu & 50 & 50 & $51350 \mathrm{gr}$ & $1000 / 200 \mathrm{gr}$ & $256.600,0$ \\
\hline Tepung sajiku & 5 & 5 & $5,135 \mathrm{~kg}$ & $8.000 / 500 \mathrm{gr}$ & $82.160,0$ \\
\hline Minyak kelapa & 12 & 12 & $12,32 \mathrm{~kg}$ & $14.000 / \mathrm{kg}$ & $172.480,0$ \\
\hline Gambas/oyong & 25 & 29 & $29,78 \mathrm{~kg}$ & $17.000 / \mathrm{kg}$ & $506.260,0$ \\
\hline Wortel & 12,5 & 15 & $15,41 \mathrm{~kg}$ & $20.000 / \mathrm{kg}$ & $308.200,0$ \\
\hline Jagung & 12,5 & 12.5 & $12837,5 \mathrm{gr}$ & $10.000 / 660 \mathrm{gr}$ & $194.507,6$ \\
\hline Semangka & 100 & 217 & $222,86 \mathrm{~kg}$ & $30.000 / 4 \mathrm{~kg}$ & $1.671 .442,5$ \\
\hline \multicolumn{5}{|c|}{ Jumlah } & $10.367 .412,70$ \\
\hline \multicolumn{6}{|c|}{ Perhitungan Biaya Bahan Makanan Menu II } \\
\hline Pastel & 100 & 100 & $1.500 \mathrm{bj}$ & $1.500 / \mathrm{bj}$ & $2.250 .000,0$ \\
\hline Gula & 16 & 16 & $16,43 \mathrm{~kg}$ & $14.000 / \mathrm{kg}$ & $230.020,0$ \\
\hline Beras & 60 & 60 & $61,62 \mathrm{~kg}$ & $10.000 / \mathrm{kg}$ & $616.200,0$ \\
\hline Ikan tuna & 25 & 25 & $25,68 \mathrm{~kg}$ & $50.000 / \mathrm{kg}$ & $1.284 .000,0$ \\
\hline Tepung terigu & 14 & 14 & $14,38 \mathrm{~kg}$ & $8.000 / \mathrm{kg}$ & $115.040,0$ \\
\hline Tepung sajiku & 5 & 5 & $5,135 \mathrm{~kg}$ & $8.000 / 500 \mathrm{gr}$ & $82.160,0$ \\
\hline Tepung roti & 20 & 20 & $20,54 \mathrm{~kg}$ & $18.000 / \mathrm{kg}$ & $369.720,0$ \\
\hline Kentang & 17 & 20 & $20,54 \mathrm{~kg}$ & $16.000 / \mathrm{kg}$ & $328.640,0$ \\
\hline Tepung terigu & 14 & 14 & $14,38 \mathrm{~kg}$ & $8.000 / \mathrm{kg}$ & $115.040,0$ \\
\hline
\end{tabular}




\begin{tabular}{|c|c|c|c|c|c|}
\hline Telur & 8 & 8 & $8.22 \mathrm{~kg}$ & $36.000 / \mathrm{kg}$ & $295.920,0$ \\
\hline Minyak & 10 & 10 & $10,27 \mathrm{~kg}$ & $14.000 / \mathrm{kg}$ & $143.780,0$ \\
\hline Gambas/oyong & 50 & 54 & $55,46 \mathrm{~kg}$ & $17.000 / \mathrm{kg}$ & $942.820,0$ \\
\hline Kacang tanah & 2,5 & 2,5 & $2,57 \mathrm{~kg}$ & $30.000 / \mathrm{kg}$ & $77.100,0$ \\
\hline Kacang panjang & 2,5 & 2,5 & $2,57 \mathrm{~kg}$ & $8.000 / \mathrm{kg}$ & $20.260,0$ \\
\hline Jagung & 2,5 & 2,5 & $2.567,50 \mathrm{gr}$ & $10.000 / 660 \mathrm{gr}$ & $38.901,5$ \\
\hline Labu siam & 2,5 & 8 & $8,22 \mathrm{~kg}$ & $4.000 / \mathrm{kg}$ & $32.880,0$ \\
\hline Kangkung & 15 & 22 & $22,59 \mathrm{~kg}$ & $20.000 / \mathrm{kg}$ & $451.800,0$ \\
\hline Nangka & 100 & 357 & $366,64 \mathrm{~kg}$ & $35.000 / 10 \mathrm{~kg}$ & 1.283 .240 \\
\hline \multicolumn{4}{|c|}{ Jumlah } & & $8.677 .521,50$ \\
\hline
\end{tabular}

\section{Perhitungan Biaya Bahan Makanan Menu III}

\begin{tabular}{|l|c|c|c|c|c|}
\hline Perhitungan Biaya Bahan Makanan Menu III \\
\hline Stik pisang & 100 & 100 & $1.500 \mathrm{bj}$ & $1.500 / \mathrm{bj}$ & $2.250 .000,0$ \\
\hline Gula & 16 & 16 & $16,43 \mathrm{~kg}$ & $14.000 / \mathrm{kg}$ & $230.020,0$ \\
\hline Beras & 60 & 60 & $61,62 \mathrm{~kg}$ & $10.000 / \mathrm{kg}$ & $616.200,0$ \\
\hline Telur ayam & 50 & 55 & $56.49 \mathrm{~kg}$ & $36.000 / \mathrm{kg}$ & $2.033 .640,0$ \\
\hline Tempe & 20 & 20 & $20,54 \mathrm{~kg}$ & $15.000 / \mathrm{kg}$ & $308.100,0$ \\
\hline Tepung terigu & 14 & 14 & $14,38 \mathrm{~kg}$ & $8.000 / \mathrm{kg}$ & $115.040,0$ \\
\hline Tepung sajiku & 5 & 5 & $5,135 \mathrm{~kg}$ & $8.000 / 500 \mathrm{gr}$ & $82.160,0$ \\
\hline Tepung roti & 20 & 20 & $20,54 \mathrm{~kg}$ & $20.000 / \mathrm{kg}$ & $410.800,0$ \\
\hline Minyak kelapa & 5 & 5 & $5,14 \mathrm{~kg}$ & $14.000 / \mathrm{kg}$ & $71.960,0$ \\
\hline Gambas/oyong & 50 & 59 & $60,59 \mathrm{~kg}$ & $17.000 / \mathrm{kg}$ & $1.030 .030,0$ \\
\hline Kacang tanah & 2,5 & 2,5 & $2,57 \mathrm{~kg}$ & $30.000 / \mathrm{kg}$ & $77.100,0$ \\
\hline Kacangpanjang & 2,5 & 2,5 & $2,57 \mathrm{~kg}$ & $8.000 / \mathrm{kg}$ & $20.560,0$ \\
\hline Jagung & 2,5 & 2,5 & $2.567,50 \mathrm{gr}$ & $10.000 / 660 \mathrm{gr}$ & $38.901,51$ \\
\hline Labu siam & 2,5 & 8 & $8,22 \mathrm{~kg}$ & $4.000 / \mathrm{kg}$ & $32.880,0$ \\
\hline Kangkung & 15 & 22 & $22,59 \mathrm{~kg}$ & 20.000 & $451.800,0$ \\
\hline Pepaya & 100 & 110 & $112,97 \mathrm{~kg}$ & $15.000 / \mathrm{kg}$ & $1.694 .550,0$ \\
\hline \multicolumn{7}{|l|}{ Jumlah } & & $9.463 .741,51$ \\
\hline
\end{tabular}

\begin{tabular}{|c|c|c|c|c|c|}
\hline \multicolumn{6}{|c|}{ Perhitungan Biaya Bahan Makanan Menu IV } \\
\hline Terang bulan & 100 & 100 & $1.500 \mathrm{bj}$ & $1.500 / \mathrm{bj}$ & $2.250 .000,0$ \\
\hline Gula & 16 & 16 & $16,43 \mathrm{~kg}$ & $14.000 / \mathrm{kg}$ & 230.020 \\
\hline Beras & 60 & 60 & $61,62 \mathrm{~kg}$ & $10.000 / \mathrm{kg}$ & 616.200 \\
\hline Ikan katombo & 50 & 50 & 1027/ekor & 2.000/ekor & $2.054 .000,0$ \\
\hline Tempe & 30 & 30 & $30,81 \mathrm{~kg}$ & $15.000 / \mathrm{kg}$ & $462.150,0$ \\
\hline Kacang tanah & 4 & 4 & $4,11 \mathrm{~kg}$ & $30.000 / \mathrm{kg}$ & $123.300,0$ \\
\hline Minyak kelapa & 10 & 10 & $10,27 \mathrm{~kg}$ & $14.000 / \mathrm{kg}$ & $143.780,0$ \\
\hline Bayam & 2 & 3 & $3,08 \mathrm{~kg}$ & $8.000 / \mathrm{kg}$ & $24.640,0$ \\
\hline Kangkung & 10 & 17 & $17,46 \mathrm{~kg}$ & $20.000 / \mathrm{kg}$ & $349.200,0$ \\
\hline Labu siam & 25 & 30 & $30,81 \mathrm{~kg}$ & $4.000 / \mathrm{kg}$ & $123.240,0$ \\
\hline Labu kuning & 20 & 27 & $27,73 \mathrm{~kg}$ & $20.000 / \mathrm{kg}$ & $554.600,0$ \\
\hline Kacang panjang & 4 & 4 & $4,11 \mathrm{~kg}$ & $8.000 / \mathrm{kg}$ & $32.880,0$ \\
\hline Jagung & 20 & 20 & $20.540 \mathrm{gr}$ & $10.000 / 660 \mathrm{gr}$ & $311.212,1$ \\
\hline Melon & 100 & 172 & $176,64 \mathrm{~kg}$ & $10.000 / \mathrm{kg}$ & 1.766 .400 \\
\hline \multicolumn{4}{|c|}{ Jumlah } & & $9.041 .622,10$ \\
\hline
\end{tabular}

\begin{tabular}{|l|c|c|c|c|c|}
\hline \multicolumn{7}{|l|}{ Perhitungan Biaya Bahan Makanan Menu V } & & \\
\hline Lalampa & 100 & 100 & $1.500 \mathrm{bj}$ & $1.500 / \mathrm{bj}$ & $2.250 .000,0$ \\
\hline Gula & 16 & 16 & $16,43 \mathrm{~kg}$ & $14.000 / \mathrm{kg}$ & $230.020,0$ \\
\hline Beras & 60 & 60 & $61,62 \mathrm{~kg}$ & $10.000 / \mathrm{kg}$ & $616.200,0$ \\
\hline Penja & 25 & 25 & $25,68 \mathrm{~kg}$ & $80.000 / \mathrm{kg}$ & $2.054 .400,0$ \\
\hline Telur & 8 & 8 & $8,22 \mathrm{~kg}$ & $36.000 / \mathrm{kg}$ & $295.920,0$ \\
\hline Jagung & 50 & 50 & $51.350 \mathrm{gr}$ & $10.000 / 660 \mathrm{gr}$ & $778.030,3$ \\
\hline
\end{tabular}




\begin{tabular}{|l|c|c|c|c|c|}
\hline Tepung terigu & 14 & 14 & $14,38 \mathrm{~kg}$ & $8.000 / \mathrm{kg}$ & $115.040,0$ \\
\hline Minyak kelapa & 10 & 10 & $10,27 \mathrm{~kg}$ & $14000 / \mathrm{kg}$ & $143.780,0$ \\
\hline Daun kelor & 24 & 36 & $36,97 \mathrm{~kg}$ & $6000 / \mathrm{kg}$ & $221.820,0$ \\
\hline Terong & 15 & 15 & $15.405,00 \mathrm{gr}$ & $1000 / 150 \mathrm{gr}$ & $102.700,0$ \\
\hline Kelapa & 11 & 11 & $11,30 \mathrm{~kg}$ & $10.000 / \mathrm{kg}$ & $113.000,0$ \\
\hline Pisang gapi & 50 & 50 & $1027 \mathrm{bj}$ & $8000 / 13 \mathrm{bj}$ & $632.000,0$ \\
\hline \multicolumn{7}{|c|}{ Jumlah } & & $7.552 .910,30$ \\
\hline
\end{tabular}

Sumber data primer, 2019

Berikut adalah tabel perhitungan biaya makanan selama satu siklus di SD/SMP IT AlFahmi Kota Palu tahun 2019:

Tabel 5 perhitungan biaya makanan satu siklus

\begin{tabular}{|c|c|}
\hline Jumlah hari & Total biaya (Rp) \\
\hline Menu I & $10.367 .412,70$ \\
\hline Menu II & $8.677 .521,50$ \\
\hline Menu III & $9.463 .741,51$ \\
\hline Menu IV & $9.041 .622,10$ \\
\hline Menu V & $7.552 .910,30$ \\
\hline jumlah biaya per siklus & $45.103 .208,11$ \\
\hline biaya bumbu 10\% & 4510320,811 \\
\hline jumlah & $49.613 .528,92$ \\
\hline $\begin{array}{c}\text { Jumlah biaya bahan } \\
\text { makanan/orang/hari }\end{array}$ & $9.661,83$ \\
\hline
\end{tabular}

Sumber data primer, 2019

\section{b. Biaya Tenaga}

Tabel 6 Perhitungan Biaya Tenaga/Bulan

\begin{tabular}{|l|c|c|c|}
\hline \multicolumn{1}{|c|}{ Jenis tenaga } & $\begin{array}{c}\text { Jumlah } \\
\text { tenaga }\end{array}$ & $\begin{array}{c}\text { Upah/gaji } \\
\text { (Rp) }\end{array}$ & $\begin{array}{c}\text { Jumlah } \\
\text { gaji/upah } \\
\text { (Rp) }\end{array}$ \\
\hline $\begin{array}{l}\text { Manajer SDM, } \\
\text { Perlengkapan, dan } \\
\text { Kebersihan }\end{array}$ & 1 & $1,000,000$ & $1,000,000$ \\
\hline Manajer Teknis & 1 & $1,000,000$ & $1,000,000$ \\
\hline Konsultan Gizi & 1 & $2,267.000$ & $2,267.000$ \\
\hline Logistik & 1 & 800.000 & 8.00 .000 \\
\hline Adminstrasi & 1 & 800.000 & 8.00 .000 \\
\hline Pengolah & 16 & 800.000 & $12,800.000$ \\
\hline Distribusi & 1 & 800.000 & 8.00 .000 \\
\hline Peralatan & 1 & 800.000 & 8.00 .000 \\
\hline Sanitasi & 1 & 1.300 .000 & 1.300 .000 \\
\hline
\end{tabular}

Sumber data primer, 2019

Berikut adalah aspek yang berkaitan dengan biaya tenaga:

Tabel 7 Perhitungan Aspek Biaya Tenaga / Bulan / 20 hari kerja

\begin{tabular}{|l|c|c|}
\hline \multicolumn{1}{|c|}{$\begin{array}{c}\text { Aspek Biaya } \\
\text { Tenaga }\end{array}$} & $\begin{array}{c}\text { Uraian } \\
(\mathrm{Rp})\end{array}$ & Jumlah (Rp) \\
\hline Gaji/ Upah & 21.567 .000 & $21.567 .000,00$ \\
\hline $\begin{array}{l}\text { Insentif } \\
\text { /Kehadiran }\end{array}$ & 25.000 & $11.000 .000,00$ \\
\hline
\end{tabular}

\begin{tabular}{|l|c|c|}
\hline Tranportasi & 16.000 & $7.040 .000,00$ \\
\hline $\begin{array}{l}\text { Asuransi } \\
\text { kesehatan }\end{array}$ & 51.000 & $1.122 .000,00$ \\
\hline Total & & $40.729 .000,00$ \\
\hline $\begin{array}{l}\text { Total biaya } \\
\text { tenaga /bulan }\end{array}$ & $40.729 .000,00$ \\
\hline $\begin{array}{l}\text { Total biaya } \\
\text { tenaga/orang/hari }\end{array}$ & $1.982,91$ \\
\hline
\end{tabular}

Sumber data primer, 2019

Keterangan :

Dari total 24 orang tenaga kerja biaya insentif berupa kehadiran, transportasi dan asuransi kesehatan terhitung hanya pada 22 orang tenaga diluar konsultan gizi dan sanitasi.

Jadi total biaya tenaga di SD/SMP IT Al-Fahmi Kota Palu tahun 2019 adalah Rp.1.982,91,/orang/hari.

c. Biaya Overhead

Dari hasil wawancara yang dilakukan didapatkan adalah biaya overhead yang berkaitan dengan penyelenggaraan makanan di SD/SMP IT Al-Fahmi terdiri dari biaya tetap yaitu barang dengan pemakaian 3 tahun, 10 tahun dan 15 tahun. Biaya tidak tetap yaitu barang habis pakai, listrik dan bahan bakar serta penyusutan. Dimana didapatkan hasil biaya overhead adalah Rp. 265,73/orang/hari.

d. Unit Cost Makanan 
Berikut adalah tabel hasil perhitungang unit cost makanan pada menu makanan yang disajikan di SD/SMP IT Al-Fahmi Kota Palu tahun 2019. Unit cost meliputi biaya bahan makanan, biaya overhead, biaya tenaga, dan profit yang dapat dilihat pada tabel dibawah ini.

Tabel 8 Perhitungan Unit Cost Makanan

\begin{tabular}{|c|l|c|}
\hline No. & \multicolumn{1}{|c|}{ Aspek Biaya } & $\begin{array}{c}\text { Jumlah } \\
(\mathrm{Rp})\end{array}$ \\
\hline 1. & $\begin{array}{l}\text { biaya bahan } \\
\text { makanan/orang/hari }\end{array}$ & $9.661,83$ \\
\hline 2. & biaya tenaga/orang/hari & 1.982 .91 \\
\hline 3. & biaya overhead/orang/hari & 265.73 \\
\hline 4. & biaya profit/orang/hari & $2.101,84$ \\
\hline 5. & total unit cost/orang/hari & $14.012,31$ \\
\hline \multicolumn{3}{|c|}{ Sumber data primer, 2019 }
\end{tabular}

Unit unit cost makanan pada menu yang disajikan pada menu makanan yang disajikan pada penyelenggaraan makan di SD/SMP Islam Terpadu Kota Palu tahun 2019 adalah Rp. 14.012,31,-./orang/hari dengan 1 kali selingan dan 1 kali makanan utama.

e. Profit

Dari hasil wawancara yang dilakukan didapatkan hasil bahwa profit atau keuntungan pada penyelenggaraan makanan di SD/SMP IT Al-Fahmi kota Palu tidak ditentukan berapa persennya, hanya saja bagaimana guru, pekerja dan staf yang ada dapat juga makan dari penyelenggaraan maknanan yang ada. Sehingga pada penelitian ini biaya profit akan di presentasikan sebanyak $15 \%$ dari total biaya makanan, biaya tenaga, dan biaya overhead. Dan biaya profit di SD/SMP IT Al-Fahmi Kota Palu tahun 2019 adalah Rp. 2.101,84,-/orang/hari.

\section{PEMBAHASAN}

1. Biaya Makanan

Biaya makanan adalah biaya-biaya yang dibutuhkan untuk menyediakan semua bahan makanan dan minuman serta bahan lain yang dibutuhkan untuk menghasilkan makanan dan minuman. Biaya ini merupakan variabel langsung karena berhubungan langsung dengan naik turunnya produksi dan pelayanan makanan yang diselenggarakan. Untuk dapat menghitung besarnya biaya makanan ini diperlukan informasi atau data berupa jumlah produksi/konsumen, standar menu, standar resep, dan standar porsi, standar harga (pasar/harga kontrak) yang digunakan di institusi tersebut. ${ }^{5}$

Berdasarkan penelitian yang dilakukan di SD/SMP IT Al-fahmi biaya makanan didapatkan adalah Rp. 9.661,83,/orang/hari, yang dihitung dengan jumlah produsen, standar menu, standar porsi dan standar harga yang ada, dimana standar harga yang dipakai adalah standar harga berdasarkan harga pasar.

Penellitian ini sejalan dengan peneitian tentang analisis biaya dan zat gizi pada penyelenggaraan makanan di Sekolah Polisi Negara (SPN) Batua Kota Makasar Sulawesi Selatan, Diperolah biaya makanan untuk tiga kali makan utama dan dua kali selingan adalah Rp.37.000/orang/hari. ${ }^{7}$

2. Biaya Tenaga 
Tenaga merupakan salah satu unsur penting dalam penyelenggaraan makanan, tampa adanya tenaga proses dalam penyelenggaraan makanan tidak akan berjalan semestinya. Biaya tenaga adalah biaya yang harus dikeluarkan untuk membayar tenaga atau kariyawan. Biaya ini merupakan variabel tidak langsung berhubungan dengan produksi makanan.

Dari hasil penelitian yang dilakukan biaya tenaga yang terdapat pada penyelenggaraan makanan di SD/SMP IT Al-Fahmi terdiri dari gaji pokok peawai, gaji atas kehadiran pegawai, transportasi pegawai, dan tunjangan kesehatan. Sehingga didapatkan biaya tenaga pada penyelenggaraan makanan di SD/SMP IT Al-famhi adalah Rp.1.982,91/orang/hari.

\section{Biaya Overhead}

Biaya overhead merupakan biaya tidak teteap yang digunakan untuk menunjang biaya operasianal. Sehingga proses penyelenggaraan makanan dapat berjalan. Biaya overhead terbagi atas biaya operasional tetap dan biaya operational tidak tetap.Biaya operasianal tetap terdiri dari gedung, lokasi, air, listrik dan telepon. Sedangkan biaya operasional tidak tetap terdiri atas iklan, promosi, trasportasi, dan bahan habis pakai. ${ }^{5}$

Dari hasil penelitian yang
dilakukan didapatkan adalah biaya
overhead yang berkaitan dengan
penyelenggaraan makanan di SD/SMP IT

Al-Fahmi terdiri dari listrik, telepon, gas, transportasi, penyusutan alat dan pemeliharaan gedung, sedangangkan biaya yang tidak ada terdiri dari iklan, promosi. Sehingga didapatkan biaya overhead pada penyelenggaraan makanan di SD/SMP IT Al-Famhi adalah sebesar Rp.265.73/orang/hari.

\section{Unit Cost}

Unit cost adalah Biaya yang melekat pada suatu produksi, biaya yang dikeluarkan untuk setiap porsi maknan dinamakan unit costmakanan, yang meliputi biaya makanan, biaya tenaga, biaya overhead dan profit. $^{8}$

Unit cost makanan pada menu yang disajikan pada menu makanan yang disajikan pada penyelenggaraan makan di SD/SMP Islam Terpadu Kota Palu tahun 2019 adalah Rp.14.012,31,-/orang /hari, dari total konsumen sebanyak 1027 orang.

Penelitian ini sejalan penelitian sejalan dengan penelitian tentang unit costmakan pasien di instalasi gizi RSUDProf. Dr. Margono Soekarjo Purwokerto, diperoleh bahwa dari hasil tender paket makanan/pasien/hari untuk kelas utama Rp 10.000,-, kelas I Rp 8.000,-, kelas II Rp 6.650,-, dan kelas III Rp 4.950,-. Perincian harga ini meliputi biaya bahan makanan, biaya bahan bakar dan biaya tenaga panyaji makanan sebanyak 28 orang dengan pelayanan makanan sampai ke pasien dengan operasional pelaksanaannya di Rumah Sakit. ${ }^{7}$ 


\section{Profit}

Profit atau laba merupakan pusat pertanggung jawaban yang masukan dan keluarannya diukur dengan menghitung selisih antara pendapatan dan pengeluaran. ${ }^{9}$

Diketahui dari hasil wawancara bahwa dari penyelenggaraan makanana yang ada pihak sekolah belum menetapkan berapa provit atau keuntungn yang diambil. Pihak sekolah mengatakan keuntungan bukan menjadi tujuan utama dari penyelenggaraan makanan yang ada. Dan peneliti mempresentasikan biaya profit sebesar $15 \%$ dari total biaya makanan, biaya tenaga, biaya overhead ${ }^{5}$. Sehingga biaya Profit yang didapatka pada penyelenggaraan makanan di SD/SMP IT Al-Fahmi adalah sebesar Rp.2.101,84/orang/hari.

\section{KESIMPULAN DAN SARAN}

Penyelenggaraan makanan di SD/SMP IT Al-fahmi Kota Palu adalah melayani 1027 orang konsumen, dengan 5 hari siklus menu, terdapat standar menu/resep, dan harga satuan makanan yang berlaku adalah harga pasar. Tenaga yang ada berjumlah 24 orang, aspek biaya tenaga terdiri atas gaji, biaya insentif, transportasi, dan tunjangan kesehatan. Biaya overheadterdiri dari biaya tetap dengan barang dengan pemakaian 3 tahun, 10 tahun dan 15 tahun. Biaya tidak tetap yaitu barang habis pakai, listrik dan bahan bakar serta 7. Agharisty E, M.Dachlan D, Yustini. Analisis biaya dan zat gizi pada penyusutan. Sehingga didapatkan biaya makanan per orang per hari adalah Rp.9.661,83,-, biaya tenaga per orang perhari adalahRp.1.982,91, biaya overhead per orang per hari adalah 265.73,-, unit cost pada Rp.14.012.31/orang/hari, dan profit yaitu Rp.2.101,84,-/orang/hari. Saran dari penelitian ini adalah hasil penelitian ini dapat menambah informasi menjadi referensi dan saran bacaan di perpustakaan, serta bermanfaat bagi peneliti selanjutnya yang melakukan penelitian serupa dan menemukan hal-hal yang baru.

\section{UCAPAN TERIMA KASIH}

Ucapan terima kasih diberikan kepada 1) Direktur Poltekkes Kemenkes Palu, 2) Ketua Yayasan Al Fahmi, 3) Kepala Sekolah SD/SMP IT Al Fahmi

\section{DAFTAR PUSTAKA}

1. Bakri B, Intiyati A, Widartika. Sistem Penyelenggaraan Makanan Institusi. Pertama. Pusat Pendidikan Sumber Daya Manusia Kesehatan. Jakarta: BPPSDM; 2018.

2. Hardiansyah, Supariasah ID. Ilmu Gizi Teori dan Aplikasi. Gizi Bayi dan Balita. 2017.

3. Taqhi SA. The Description of Food Procurement Systemat the Hubulo Islamic. Media Kesehat Masy Indones. 2014;

4. Hardinsyah IDNS. Ilmu Gizi Teori dan Aplikasi. Jakarta: Penerbit Buku Kedokteran EGC; 2016. 621 p.

5. Rochimiwati SN, Mas'ud H, Arifin NA. Analisis Menu Makanan Biasa Kelas III di RSUD Massenrempullu Kabupaten Enrekang. Media Gizi Pangan. 2014;17(1).

6. Ilmi N, Dachlan DM, Yustini. Gambaran Sistem Penyelenggaraan Makanan Di Pondok Pesantren Putri Ummul Mukminin Makassar. 2014;38(17):2848-53.

penyelenggaraan makanan di Sekolah Polisi Negara (SPN) Batua Kota Makasar 
Sulawesi Selatan. 2013;

8. ASDI. Peran Gizi Dalam Kelangsungan Hidup Manusia. Semarang; 2007.
9. Halim, Supomo. Akutansi Manajemen. Yogyakarta: BPPE; 2005 